\title{
Design and implementation of the remote intelligent measurement and control system of greenhouse parameters
}

\author{
Lin Zhao, a, Yining Liü,b \\ ${ }^{1}$ School of Application Technology,University of Science and Technology Liaoning , \\ Anshan Liaoning ,China 114000 \\ ${ }^{2}$ School of Electronics and Information Engineering,Liaoning Technical University , \\ Huludao Liaoning ,China 125105 \\ A605199887@qq.com, b349708563@qq.com
}

Keywords: Greenhouse environment, Intelligent sensor, Remote monitoring system, Data acquisition.

Abstract. This design is a measurement and control system of greenhouse ecological parameters. It realizes the data acquisition of temperature, humidity and carbon dioxide on the site, implement the data transmission and display function by using the data acquisition system which consist of the converter, data collector and monobus sensor.

\section{Introduction}

With the development of social economy, more and more country pay attention to facility agriculture. In facility agriculture,greenhouse construction engineering is important part of the development of modern agriculture as the advanced stage of the development of facility agriculture. Greenhouse modernization is mainly reflected on the monitoring of greenhouse environment. Greenhouse environment control is a comprehensive technology, in order to create optimal environmental conditions which is suitable for crop growth, devisers should be familiar with the characteristics and requirements of greenhouse environment at the first step, then formulate the overall design scheme and control strategy and put them into practice. This system implement the remote monitoring of greenhouse environment by using serial port, network system and single-chip microcomputer technology. It can monitor the real-time change of environmental parameters, as well as make the corresponding real-time control.[1,2]

\section{The overall design of the greenhouse intelligent monitoring system}

The overall structure of system

The star structure is easy to control and maintain, therefore, based on the actual situation, the system uses a star network control structure based on the upper computer which combine with many sets of lower computer. The upper computer is the central node of the entire system as the central monitoring station; each lower computer is a branch node of the entire system as the on-site control substation. Central monitoring station unify the management and the configuration to manage the monitoring substation, each monitoring substation could work independent or online. System develop a specialized monitoring software, which aim at the specific circumstance of the equipment which are monitored, by adopting the combination of RS485 bussing technique and TCP/IP network communication,it implements the design of the remote environment monitoring by gathering multipath environment data of digital sensor simultaneously and put these data through the Internet publishing on the network . The system architecture is shown in Figure 1. 


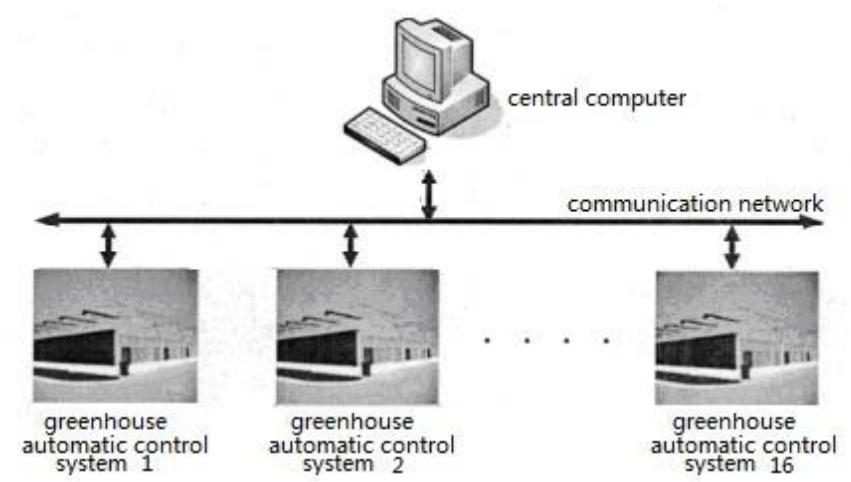

Figure 1. The structure diagram of control system

The database server is used to store the greenhouse environment data and acquisition system operating parameter in order to provide monitoring computer read and set its own working condition in running time. The administrator can access and modify the parameters in the database through the browser.The web application server could publish the data on the internet and accept querying and browsing by any user on the internet and allow the authorized users to modify the monitoring computer working parameter then store into database server. The monitoring computer will query some basic parameters in the database periodically, and adjust its working condition based on these parameters, thus implements the romote setup of monitoring computer parameters.

\section{single greenhouse structure and functions of each module}

The single green house structure is shown in Figure 2.

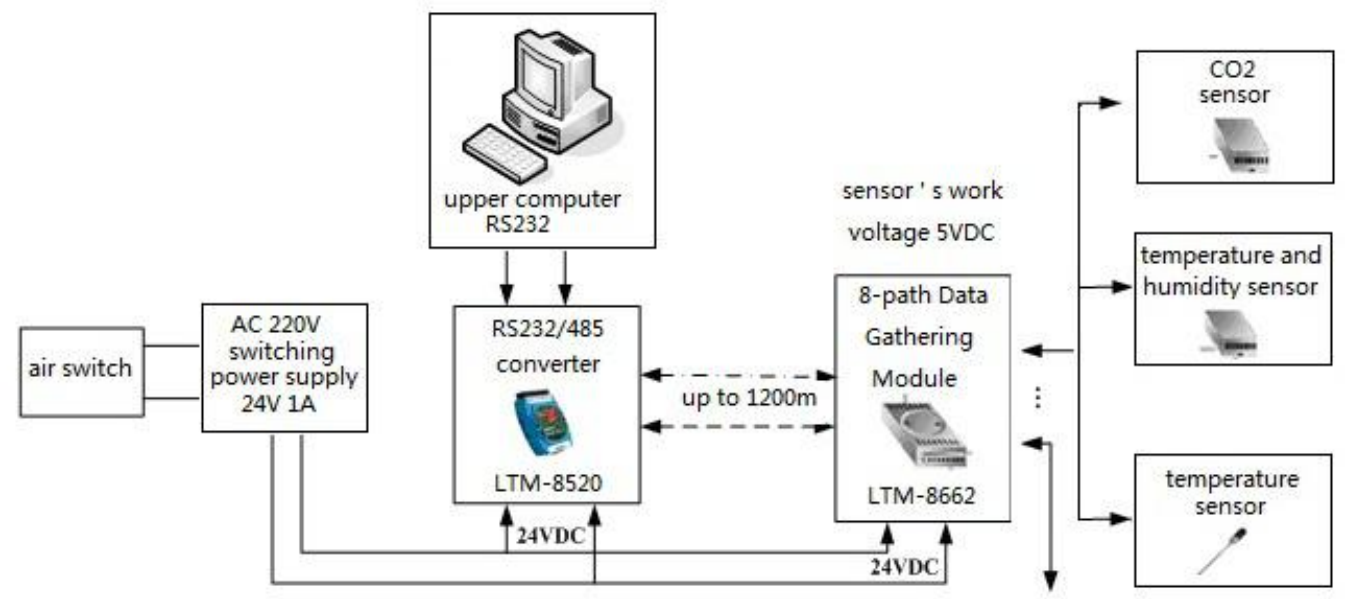

Figure 2. Single greenhouse structure

\section{RS-232/485 converter}

The communication methods of RS485 is used to implement the communication between upper computer and the intelligent terminal or intelligent humiture sensor in the intelligent greenhouse monitoring system, the intelligent terminal or intelligent humiture sensor is used to receive the set command, data acquisition command and output control data command which is sent by upper computer,executing respectively the corresponding program through judging different command. This system adopts the stand-up isolation RS232/485 conversion module LTM - 8520 .

Data acquisition module[3,4]

The system select the economical ITU collection control center LTM-8662. LTM-8662 implement the unification between ITU bus and 1-wire bus, it can process the product information of ITU bus and 1-wirebus at the same time. LTM-8662 combines all the function of LTM8000 series module and implement the connection between two-stage communication network. One stage face to upper computer RS-485 network,LTM-8863 module is used as substation; ITU bus, another stage,can 
support 8 path(sixty four) hybrid junction of various ITU, and send pick-up information to upper computer and control information to ITU.

LTM8901 “1-wire bus" humiture probe ITU

LTM8901 humiture probe ITU can directly digital output, support networking less-Point Test, the sensor link to each other by three-core cable,with the advantage of wiring easy and low cost, the distance between the testing module and sensor can run up to $50 \mathrm{~m}$. Lower power dissipation, no AC power.integration humiture and low cost.

-DS18B20 Digital temperature sensor

DS18B20 Digital temperature sensor,which is produced by Dallas semiconductor company, is the first temperature sensor that can support 1-wire bus interface. It can directly digital output, ensure measurement accuracy, easily implement the automatic identification and calibration of sensor, improve the function of multipoint temperature and humidity test system, configure more flexible, wiring easier and expend easier.measurement range of temperature is in $-55^{\circ} \mathrm{C} \sim+125^{\circ} \mathrm{C}$, the accuracy is $\pm 0.5^{\circ} \mathrm{C}$ in the range of $-10 \sim+85^{\circ} \mathrm{C}$.

LTM-8803-CO2 1-wire Bus CO2/ temperature sensor

LTM-8803-CO2 1-wire Bus CO2/ temperature sensor is a multifunction digital and networked sensor. High precision, function integration, convenient on-site calibration / convenient installation, its perfect combination of economy, convenience and advancement the greenhouse parameter monitoring system.will be improved. Range: 0 2000ppm.

\section{System function}

-Remote Data Collection and real-time data collection.

- alarm function.

- Timing save data and save the data manually.

-real-time display on simulative screen.

-Transfer to each user's home through network.

\section{The main technological indexes of system}

-Temperature: measurement range: $-55^{\circ} \mathrm{C} \sim+125^{\circ} \mathrm{C}$, measurement accuracy: $\pm 0.5^{\circ} \mathrm{C}\left(-10^{\circ}\right.$ $\left.\mathrm{C} \sim 85^{\circ} \mathrm{C}\right) ; \pm 2^{\circ} \mathrm{C}\left(-55^{\circ} \mathrm{C} \sim+125^{\circ} \mathrm{C}\right)$

-Humidity: measurement range: $1 \% \sim 99 \% \mathrm{RH}$, measurement accuracy: $\pm 2 \% \mathrm{RH}\left(25^{\circ} \mathrm{C}\right)$

-CO2: measurement range: $0 \sim 10000 \mathrm{ppm}$, sensitivity: $\triangle \mathrm{EMF}=15-30 \mathrm{Mv}(350-1000 \mathrm{ppm} \mathrm{CO} 2)$

\section{Design of the greenhouse environment data acquisition software}

\section{Program design of temperature measuring module}

Main function of DS18820 main program is provide real-time data for measuring temperature display, read temperature and processing, so that update the data temperature is measured every second.

Algorithms of the main program

\section{Start:}

(1) While time $<1$ s do

(2)Call the display subroutine

(3)If the first power up!=1 then

(4)output the temperature, Temperature calculation processor display the data refresh

(5)send the temperature-conversion command

End

The main flow chart of data acquisition system is shown in figure3. 


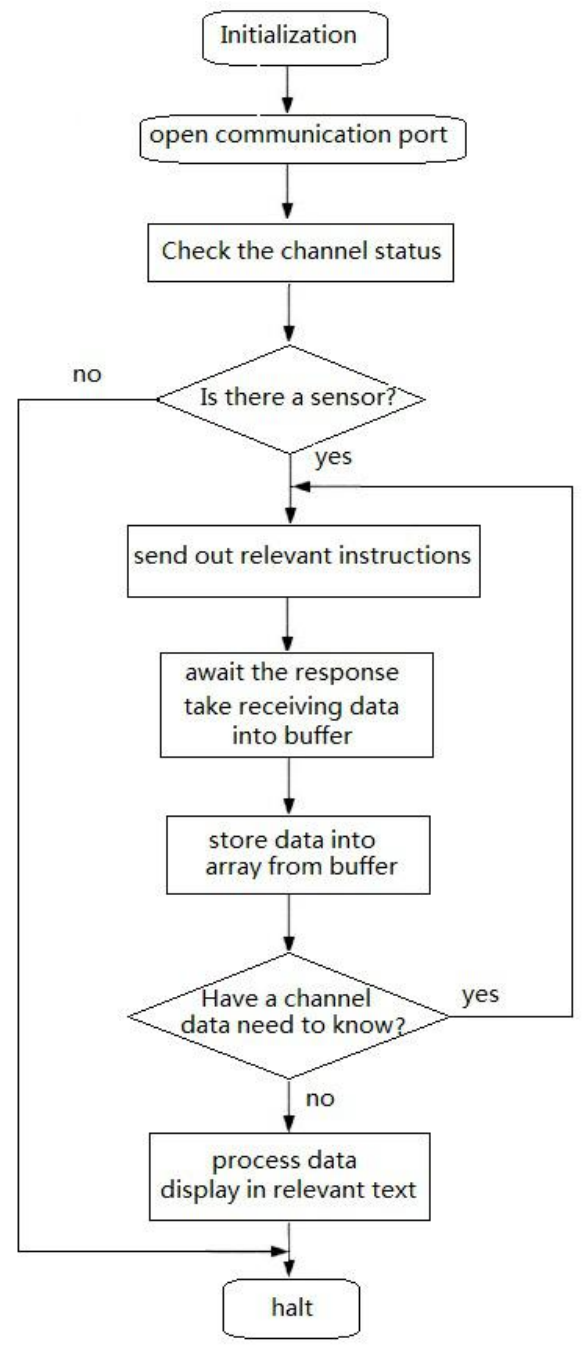

Figure 3. Main flow chart

\section{Conclusions}

System analyze and research the measurement and control system of greenhouse ecology parameter with starting of theoretical design and practical making, based on traditional greenhouse measurement, improving aspects of measurement and monitoring to implement an acquisition control system which integrate with acquisition and controlling.System has the advantage of simple structure, convenient debugging, on-site installation, easy to be extended and also strong antijamming capability and reliable long-distance transportation. Of course, the issue has greatly improved space, and we expect the issue could get improved continuously in the future.

\section{References}

[1] Li Peng.(2000)Research of greenhouse detection control system [J].Computer engineering.2000 (12):p.194

[2].Yunfeng Ma,Design of agriculture greenhouse control system based on bussing technology[J], Microcomputer \& Its Applications.2002(3),p.13

[3] Min li, Chen Meng.Design of temperature and humidity sensor based on 1-wire bus[J].Sensor World, 2003(4)

[4] Baoling Shi, DS18820 Analysis of digital temperature sensing technology [J]. New technologies and products, 2011 